\title{
Comparison of standard lactation curve models using fortnightly milk records in Frieswal cattle
}

Amit Kumar Dohare ${ }^{1}$, B. Singh ${ }^{1}$, Med Ram Verma ${ }^{1}$, Bangkeng Perme ${ }^{2}$, Vijay Bahadur Sharma ${ }^{1}$, Neha Gupta ${ }^{1}$ and Shashank Kshandakar ${ }^{1}$

\begin{abstract}
1. Division of Livestock Economics, Statistics \& Information Technology, Indian Veterinary Research Institute, Izatnagar, Bareilly, Uttar Pradesh, India; 2. Division of Animal Nutrition, Indian Veterinary Research Institute, Izatnagar, Bareilly, Uttar Pradesh, India.

Corresponding author: Amit Kumar Dohare, e-mail: dr.doharevet@gmail.com, BS: bsingh@ivri.res.in, MRV: medramverma@rediffmail.com, BP: bangkeng.perme@gmail.com, VBS: drvijaybharadwaj@gmail.com, NG: nehaguptaivri2012@gmail.com, SK: skshandakar@gmail.com

Received: 31-07-2014, Revised: 10-09-2014, Accepted: 16-09-2014, Published online: 18-10-2014
\end{abstract}

doi: 10.14202/vetworld.2014.831-834. How to cite this article: Dohare AK, Singh B, Verma MR, Perme B, Sharma VB, Gupta N, Kshandakar S (2014) Comparison of standard lactation curve models using fortnightly milk records in Frieswal cattle, Veterinary World 7(10): 831-834.

\begin{abstract}
Aim: The aim was to compare standard lactation curve models using fortnightly milk records in Frieswal cattle.

Materials and Methods: A total of 2904 fortnightly milk yield (FMY) records from 132 Frieswal cattle maintained at Military Farm, Bareilly, Uttar Pradesh were taken for study. The Wood (WD), Morant and Gnanasakthy (MG), Mitscherlich $\mathrm{x}$ Exponential (ME), and Wilmink (WK) models were fitted on average FMY (AFMY) by nonlinear regression using statistical package SAS 9.3 version. The goodness of fit of models was judged by the adjusted coefficient of determination $\left(\right.$ Adj. $\mathrm{R}^{2}$ ) and root mean square error.

Results: The AFMY ranges from $127.09 \mathrm{~kg}$ (first fortnight) to $110.04 \mathrm{~kg}$ (last fortnight) with peak fortnight yield of $189.51 \mathrm{~kg}$ and peak period at fourth fortnight. Predicted peak yield by different models ranges from 182.7 to $190.2 \mathrm{~kg}$. The herd average milk yield was predicted with a high degree of accuracy (Adj. $\mathrm{R}^{2}>92 \%$ ) by all models with the maximum accuracy (Adj. $\mathrm{R}^{2}=99.20 \%$ ) obtained by ME model followed by MG (Adj. $\mathrm{R}^{2}=98.8 \%$ ) and WK model (Adj. $\left.\mathrm{R}^{2}=96.0 \%\right)$.
\end{abstract}

Conclusion: The ME model provided best fit for FMY data in Frieswal cattle followed by WK and MG model, whereas WD model fitted least.

Keywords: Frieswal cattle, fortnightly milk yield, lactation curve model, peak yield.

\section{I ntroduction}

Milk production is one of the most important economic traits in dairy cattle. Improving milk productivity of Indian cow has been pursued since many decades in India. It is conceded that average yield of an Indian cow is very low, at about $1000 \mathrm{~L} /$ lactation. Cross breeding with exotic European breeds is the best alternative to improve the genotype and milk producing capability of the low yielding Indian cows. Recognizing the effectiveness of cross breeding and by utilizing the crossbred cattle population available at Military Farms in India a new synthetic breed was evolved named "Frieswal." The Frieswal synthetic breed has around 62\% Friesian and 38\% Sahiwal inheritance, capable of producing $4000 \mathrm{~kg}$ milk with $4 \%$ butterfat in a lactation of 305 days and a calving interval of 13 months under good management conditions [1].

The lactation curve is one of the important tools to understand and evaluate the physiological performance of milk production and to establish better management strategies [2,3]. To describe milk yield

Copyright: The authors. This article is an open access article licensed under the terms of the Creative Commons Attributin License (http:// creative commons.org/licenses/by/2.0) which permits unrestricted use, distribution and reproduction in any medium, provided the work is properly cited. pattern throughout the lactation in domestic animals, various mathematical models have been proposed. Mathematical models for describing a lactation curve include negative exponentials, incomplete gamma, and polynomials, all of which can estimate the milk yield average at a given time [4]. The lactation curve is also important because its wide characterization of the animal production throughout lactation allows estimating the peak yield (PY), the time of peak, days in milk, and the total milk yield [5].

The objectives of the current study were to compare four models (Wood [WD], Morant and Gnanasakthy [MG], Mitscherlich x Exponential [ME] and Wilmink [WK]) and their adequacy of fit to the lactation curve in Frieswal cattle.

\section{Materials and Methods}

\section{Data collection}

The data for the present study were collected from milk yield records of Frieswal cattle from history-cum-pedigree sheets and daily milk recording registers maintained at Military Dairy Farm, Bareilly, Uttar Pradesh. A total of 2904 fortnightly milk production records from 132 Frieswal cattle that started their lactation after 1 April 2011 and ended their lactation in March 2013 were used. 


\section{Lactation models}

WDs model

The most extensively used function for lactation curve is the gamma type function proposed by Wood [6] to model lactation curve of dairy animals.

$\mathrm{Y}_{\mathrm{t}}=\mathrm{at}^{\mathrm{b}} \mathrm{e}^{-\mathrm{ct}}$

where, $Y_{t}$ is average milk yield $(\mathrm{kg})$ in $t^{\text {th }}$ fortnight; a is scale parameter or milk yield at the beginning of lactation; $b$, rate of change from initial production to maximum yield; c, rate of change from maximum yield to the end of lactation.

MG model

Morant and Gnanasakthy [7] proposed lactation curve model for proportional rate of change in milk production,

$\mathrm{Y}_{\mathrm{t}}=\exp \left(\mathrm{a}-\mathrm{bt}+\mathrm{ct}^{2} / 2+\mathrm{d} / \mathrm{t}\right)$

where, a is the logarithm of expected yield at 150 days of lactation; b is the principal parameter describing the rate at which yield is changing at 150 days of lactation; $c$ is the second shape parameter and is measure of extent to which persistency itself changes during lactation; and $\mathrm{d}$ is the rate of increase in yield in early lactation.

\section{ME model}

Rook et al. [8] found that the lactation curve model could be written as a product of two functions; one is the monotonic increasing with finite asymptote and the other monotonic decreasing. The best fitting of a model known as ME is defined as:

$\mathrm{Y}_{\mathrm{t}}=\mathrm{a}\left(1-\mathrm{b} \mathrm{e} \mathrm{e}^{-\mathrm{ct}}\right) \mathrm{e}^{-\mathrm{dt}}$

where, a is scale parameter or milk yield at the beginning of lactation; $b$ is a parameter related to the rate to reach PY; $c$ is a parameter related to maximum milk yield; $d$ is a parameter related to curve changes after maximum yield.

\section{WK model}

Wilmink [9] introduced two lactation models. In the first model, a quadratic term was added, and an adjustment made to the exponential term. This model (WL) was then adjusted to obtain the second model by dropping the quadratic term from the initial function.
The factor $\mathrm{k}$ was set equal to 0.05 and is associated to the time of PY. Olori et al. [10] estimated this factor to be 0.61 .

$\mathrm{Y}_{\mathrm{t}}=\mathrm{a}+\mathrm{be} \mathrm{e}^{-\mathrm{kt}}+\mathrm{ct}$

where, a is milk production before lactation, b, associated to peak day, c is associated as decrease in production after the lactation peak.

\section{Statistical analysis}

The models were fitted by nonlinear regression to the data described above using PROC NLIN statement of the statistical package SAS 9.3 version (SAS institute Inc. 2011. Cary, NC, USA). Estimates of the parameters, peak period (PP), and peak milk yield of each of the models were obtained. The most suitable model was identified on the basis of the highest value of the adjusted coefficient of determination (Adj. $\mathrm{R}^{2}$ ) and the lowest value of the root mean square error (RMSE). Adj. $\mathrm{R}^{2}$ is similar to $\mathrm{R}^{2}$, but it is adjusted for the number of parameters in the model. Residuals obtained by these functions were plotted graphically.

\section{Results and Discussion}

The WD, MG, ME, and WK models were fitted to average fortnightly milk yields (AFMY) of Frieswal cattle for the lactation period of 22 fortnights. Estimated parameters along with their standard error for the different models are presented in Table-1.

The AFMY increased from $127.09 \mathrm{~kg}$ in $1^{\text {st }}$ fortnight to a PY of $189.51 \mathrm{~kg}$ in $4^{\text {th }}$ fortnight and subsequently declined to $110.04 \mathrm{~kg}$ in the last fortnight (Figure-1). Predicted PY by different models ranges from 182.7 to $190.2 \mathrm{~kg}$, but ME model predicted very close PY (192.2 kg) to the observed value (Table-1). Nearly same PY was reported in crossbred cows $[11,12]$. However, lower PY were reported in HF crossbred cows [13]. Fourth fortnight was found to have PY as predicted by ME and MG models whereas WD and WK models predict PY in fifth fortnight. Whereas other Holstein $\mathrm{x}$ Zebu cows required 71 days to reach the peak [14], contrary to this, in humid tropic of Veracruz, Mexico the maximum time to peak production was found between 23 days to 26 days in 68 F1 Holstein $x$ Zebu cows $[15,16]$.

It was observed that the WD model gave the least fit than other lactation curve model(s) in the present

Table-1: Estimated parameters along with their standard error and predicted PP and PY for the different lactation curve models, together with measures of goodness of fit.

\begin{tabular}{|c|c|c|c|c|c|c|c|c|}
\hline \multirow[t]{2}{*}{ Model } & \multicolumn{6}{|c|}{ Estimated parameters } & \multicolumn{2}{|c|}{$\begin{array}{l}\text { Measures of } \\
\text { goodness of fit }\end{array}$} \\
\hline & $\mathbf{a}$ & b & c & d & PP & PY (kg) & Adj. $\mathbf{R}^{2}(\%)$ & RMSE \\
\hline WD & $152.515(5.050)$ & $0.283(0.032)$ & $0.055(0.004)$ & & 5 & 182.7 & 92.7 & 6.71 \\
\hline MG & $5.576(0.028)$ & $-0.044(0.004)$ & $0.001(0.000)$ & $-0.669(0.038)$ & 4 & 188.4 & 98.8 & 2.69 \\
\hline ME & $217.369(2.059)$ & $1.089(0.097)$ & $1.009(0.085)$ & $0.029(0.001)$ & 4 & 190.2 & 99.2 & 2.30 \\
\hline WK & $215.673(3.046)$ & $-137.146(10.687)$ & $-4.787(0.214)$ & & 5 & 185.2 & 96.0 & 4.97 \\
\hline
\end{tabular}

$\mathrm{PP}=$ Peak period; $\mathrm{PY}=$ Peak yield; $\mathrm{WD}=$ Wood; $\mathrm{MG}=$ Morant and Gnanasakthy; $\mathrm{ME}=$ Mitscherlich $\times$ Exponential;

WK=Wilmink; RMSE=Root mean square error; Adj. $\mathrm{R}^{2}$ : Adjusted coefficient of determination; The figures in parentheses are standard errors 


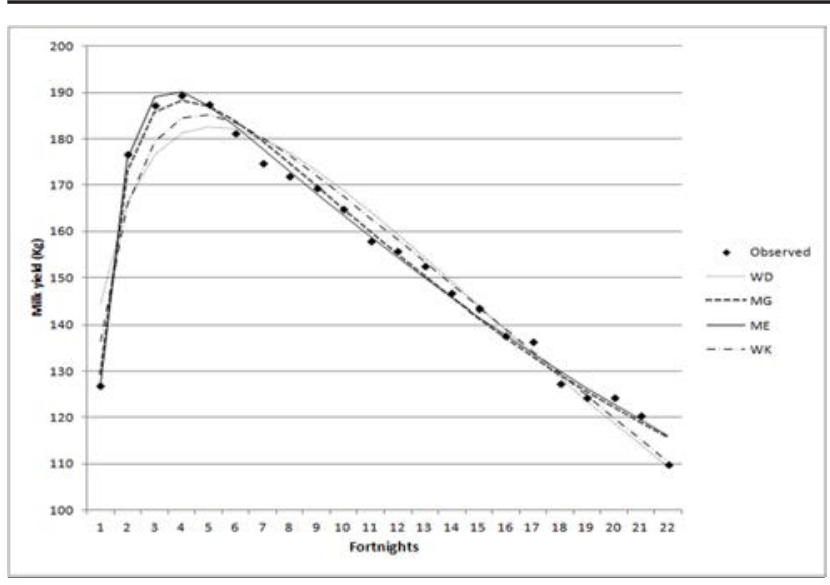

Figure-1: Average fortnightly milk yields and predicted value for different lactation curve models.

study (Figure-1). It gave the lowest Adj. $\mathrm{R}^{2}$ value (92.7\%), with the highest RMSE value $(6.72 \mathrm{Kg})$ (Table-1). The values of PP are higher, and PY are lower, corresponding to WDs model, than their respective observed values. Thus, WD model has a tendency to overestimate PP but it underestimates PY. Similar findings have been reported by different researchers in different breeds of cattle $[10,13,17]$. Contrary to the present findings, lower $\mathrm{R}^{2}(82.73 \%)$ values were reported in Sahiwal cattle [18]. The WK model gave a higher Adj. $\mathrm{R}^{2}$ value (96\%) with a comparatively lower RMSE value $(4.97 \mathrm{~kg})$. Nearly, similar findings were reported in Holstein-Friesian cows [10]. The MG model showed a better fit than WD and WK models with high Adj. $\mathrm{R}^{2}$ value (98.8\%) and lower RMSE value $(2.69 \mathrm{~kg})$. The ME model gave the highest Adj. $\mathrm{R}^{2}$ value (99.2\%) and the lowest RMSE value $(2.30 \mathrm{~kg})$. The findings were in corroboration with the finding of other authors [11,19].

The residuals of the FMY estimated by four different lactation curve models are graphically presented in Figure-2. It was observed that the errors in prediction of FMY using MG and ME model were lower in comparison to other models. The estimated values of predicted PP and PY obtained from ME model were approximately equal to observed values. Thus, the best fit model was ME, which was better than other models for prediction of milk yield in Frieswal cattle.

\section{Conclusion}

The AFMY was predicted with a high degree of accuracy (Adj. $\mathrm{R}^{2}>92 \%$ ) by all the models. However, there were marginal differences among Adj. $\mathrm{R}^{2}$ values. The ME model showed the best fit for data with the maximum Adj. $\mathrm{R}^{2}$ values and minimum RMSE for predicting FMY in Frieswal cattle. The models with four parameters predicted PY and PP much closer to observed value than models with three parameters.

\section{Authors' Contributions}

AKD and BS designed the study. BP and SK contributed in data collection from the study area. AKD conducted study and analyzed the data. MRV,

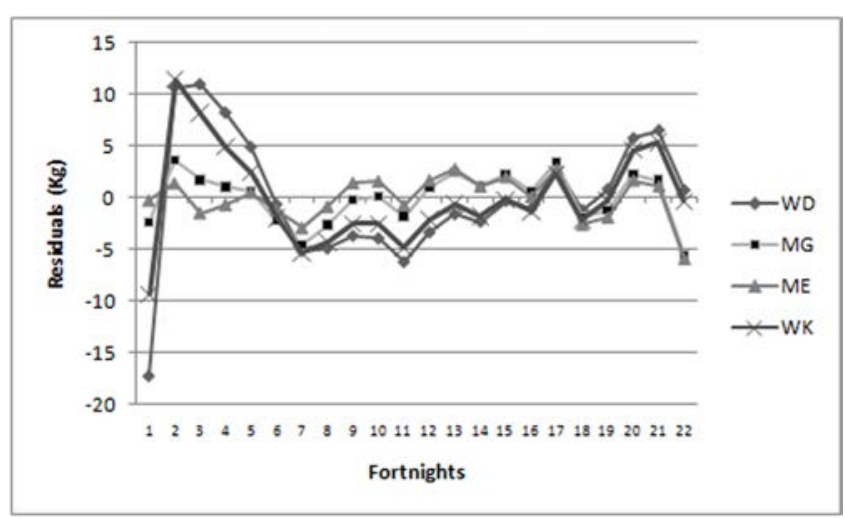

Figure-2: Residuals of the fortnightly milk yield for different lactation curve models.

VBS, and NG drafted the manuscript and revised the manuscript. All authors read and approved the final manuscript.

\section{Acknowledgments}

The authors are grateful to the Deputy Director General, Military Farms, New Delhi for permitting to use the required data. We are also thankful to the Director, IVRI for providing necessary facilities to conduct this research work.

\section{Competing I nterests}

The authors declare that they have no competing interests.

\section{References}

1. Lakshmi, B.S., Gupta, B.R., Prakash, M.G., Sudhakarn, K. and Sharma, S. (2010) Genetic analysis of the production performance of Frieswal cattle, Tamil Nadu J. Vet. Anim. Sci., 6(5): 215-222.

2. Ossa, G.S., Torregroza, L.S. and Alvarado, L. (1997) Determination of the lactation curve in crossbred cows from a dual purpose herd in the Caribbean Region of Colombia. Rev. Corpoica., 2(1): 54-57.

3. Osorio, M.M. and Segura, J.C. (2005) Factors affecting the lactation curve of dual purpose Bos taurus x Bos indicus cows in the humid tropics of Tabasco, Mexico. Тес. Реси. Mex., 43(1): 127-137.

4. Masselin, S., Souvant, D., Chappoutot, P. and Milan, D. (1987) Adjustment models for lactation curves. Ann. Zootech., 36(2): 171-206.

5. Ferreira, E.B. and Bearzoti, E. (2003) Comparação de métodos no ajustamento de curvas de lactação de bovinos por meio de simulação. Ciên. Agrotecnologia., 24(5): 865-872.

6. Wood, P. (1967) Algebraic model of the lactation curve in cattle. Nature, 216: 164-165.

7. Morant, S. and Gnanasakthy, A. (1989) A new approach to the mathematical formulation of lactation curves. Anim. Prod., 49(2): 151-162.

8. Rook, A., France, J. and Dhanoa, M. (1993) On the mathematical description of lactation curves. J. Agric. Sci., 121: 97-102.

9. Wilmink, J. (1987) Comparison of different methods of predicting 305-day milk yield using means calculated from within-herd lactation curves. Livest. Prod. Sci., 17: 1-17.

10. Olori, V., Brotherstone, S., Hill, W. and McGuirk, B. (1999) Fit of standard models of the lactation curve to weekly records of milk production of cows in a single herd. Livest. Prod. Sci., 58(1): 55-63.

11. Prasad, S. (2007) An algebraic model from mitscherlich function to describe lactation curves of dairy animals. $J$. 
Appl. Anim. Res., 31(2): 121-123.

12. Kumar, N., Eshetie, A., Abreha, T. and Yizengaw, H.A. (2014) Productive performance of indigenous and HF crossbred dairy cows in Gondar, Ethiopia. Vet. World, 7(3): 177-181.

13. Banu, R., Singh, A., Malhotra, R., Gowane, G., Kumar, V., Jaggi, S., Verghese, E., Gandhi, R., Chakravarty, A. and Raja, T. (2012) Comparison of different lactation curve models in Karan Fries cattle of India. Indian J. Anim. Sci., 82(11): 1377-1380.

14. Cervantes, A.P., Fernandez, L. and Ponce, C.P. (2006) Characterization of lactation curves in production and major components of milk in different breeds and crosses in Mexican tropical conditions (in Spanish). Rev. Salud. Anim., 28(2): 90-95.

15. Vadillo, J.C., Jose, C.A.V., Rodriguez, M.R.A. and
Rocher, C. (2012) Shapes of lactation curves of F1 (Holstein $\mathrm{X}$ Zebu) cows in the humid tropic of Veracruz, Mexico. Int. J. Anim. Vet. Adv., 4(6): 370-377.

16. Lemus-Ramirez, V., Guevara-Escobar, A. and GarciaMuniz, J.G. (2008) Lactation curve and change in body weight of grazing Holstein-Friesian cows. Agrociencia., 42(7): 753-765.

17. Cilek, S. and Keskin, I. (2008) Comparison of six different mathematical models to the lactation curve of Simmental cows reared in Kazova state farm. J. Anim. Vet. Adv., 7: 1316-1319.

18. Dongre, V.B., Gandhi, R.S. and Singh, A. (2012) Comparison of different lactation curve models of Sahiwal cows. Turk. J. Vet. Anim. Sci., 36(6): 723-726.

19. Prasad, S. (2003) Modeling of lactation curves of dairy animals. J. Appl. Anim. Res., 24(1): 79-84. 